\title{
Questão de tempo: o fluxo dos sentidos influenciado pelo ritmo, na ótica de Bob Wilson, Andrei Tarkovsky e Oliver Sacks
}

Question of time: the flow of the senses influenced by the rhythm, in the view of Bob Wilson, Andrei Tarkovsky and Oliver Sacks

Lucas Pinheiro ${ }^{1}$

Isa Kopelman ${ }^{2}$

Thais D'Abronzo 


\section{Resumo}

O presente artigo busca refletir de qual forma o ritmo ralentado, presente nas encenações de Robert Wilson, seja capaz de alterar a percepção e apreensão da obra artística por parte dos atores e espectadores. Para tal, buscou-se uma intersecção dos ideais de Wilson, como a "câmara lenta" e o "ato de fotografia", com as reflexões do neurologista Oliver Sacks e do diretor de cinema Andrei Tarkovsky.

Palavras-chave: Robert Wilson; Oliver Sacks; Tarkovsky; ritmo lento; percepção
Keywords: Robert Wilson; Oliver Sacks; Tarkovsky; slow pace; perception 


\section{O tempo de Bob Wilson}

Uma das principais características que permeiam os espetáculos do encenador norte-americano Robert Wilson (1941 - ) é o tempo.

O tempo necessário para que as imagens, as cenas, as ações e os acontecimentos sejam construídos no palco, durante as encenações, torna-se um dos pilares que sustentam a estética e as investigações artísticas presentes nos trabalhos de Bob Wilson.

É importante ressaltar que o uso do ritmo, na perspectiva Wilsoniana, esta intrinsicamente ligada a relações e reflexões que o encenador viveu no decorrer de sua vida. Portanto, para que se possa compreender de quais formas se dá a utilização do tempo nos espetáculos de Wilson, se faz necessário conhecer como este ralentar rítmico o afetou enquanto pessoa e artista.

Em 1941, em uma pequena cidade dos Estados Unidos, Wacco, no Texas, nasce Robert Wilson. Quando criança, Wilson apresentava dificuldades no aprendizado na escola, principalmente com questões relacionadas a ler e escrever, soma-se a isto seu distúrbio com a fala: era gago. Estes fatos acabaram por gerar uma criança relativamente solitária, com dificuldades de interação que, naturalmente, o fizeram "fechar-se" em seu próprio mundo, começando a desenhar. [Holmberg, 1996 e Shevtsova, 2007].

Aos dezessete anos, Wilson encontra-se com Byrd Hoffman, uma professora de ballet de sua cidade natal - que estava com pouco mais de setenta anos - e que é considerada a "primeira artista que ele conhecera" [Shevtsova, 2007, p.1]. É esta senhora, professora de dança, que através de exercícios de relaxamento físico e de extensão do tempo para realizar o ato da fala, acaba por fazer com que Wilson "cure" seus distúrbios vocais.

Em uma entrevista concedida para o documentário Absolute Wilson, com direção de Katharina Otto-Bernstein e lançado em 2006, Bob Wilson reflete sobre o como sua percepção rítmica do mundo mudou após o seu encontro com Byrd Hoffman:

Havia uma mulher que ensinava dança, ballet, para jovens pessoas em Wacco. Foi provavelmente a primeira artista que tive contato [...] Seu nome era Byrd Hoffman e ela disse para mim um dia: "Você deveria levar mais tempo para falar. Desacelerar tudo.”, e isso foi incrível, em questão de seis, oito meses foi muito mais fácil para eu falar. Mais ainda, como minha percepção do mundo mudou, desacelerando-o [Excerto de entrevista retirada do documentário Absolute Wilson, 2006, 1min].

O contato de Wilson com Byrd Hoffman foi possivelmente o começo de sua inquietação acerca dos tempos e ritmos que permeiam a vida cotidiana. Como o próprio diz no documentário Absolute Wilson, toda a sua percepção de mundo alterou-se quando ele simplesmente desacelerou seus ritmos e a forma de relacionar-se com o mundo. Hoffman o ajudou a se livrar de seus distúrbios vocais ensinando-o a "relaxar a tensão física e 'apenas relaxar', deixar a energia fluir para que ela não ficasse bloqueada" [Brecht, 1978, p.14].

Ao depararmos com o relato que Luiz Roberto Galizia [2004, p.102] faz dos la- 
boratórios ${ }^{4}$ propostos por Robert Wilson e os Byrds ${ }^{5}$, podemos notar que a "metodologia" que Hoffman utilizou anos antes em Wilson, - a insistência em se perceber mais e dar tempo para as coisas acontecerem -, permeou sua noção de pensar e fazer teatro. Em determinados exercícios propostos, era solicitado aos atores que houvesse a busca por um estado de relaxamento ${ }^{6}$, para concentrarem-se na "variedade de pensamentos que lhes vinham à mente, quando se proporciona ao corpo um tempo a mais para movimentar-se"; dar a devida atenção ao que ocorre no corpo quando o mesmo "apresenta-se" em situações na qual o espaço-tempo, e seu contato com ele, é dilatado; suas alterações físicas, assim como as alterações nas camadas mais internas e subjetivas da consciência.

Este contato do corpo com um espaço-tempo dilatado é a chamada "câmara lenta" tão presente nas encenações de Wilson, e que, esteticamente, pode-se dizer que seja sinônimo de seu estilo teatral. Não se procurava nesses laboratórios um "efeito câmara lenta" mas o ralentar das ações, a fim de se alcançar o relaxamento do corpo, para que, desta forma, os atores fossem capazes de dispor de tempo em prol de uma percepção maior de si mesmos.

Tentar enquadrar toda uma noção de dilatação de tempo, ritmo e percepção numa espécie de moldura ou numa "técnica" de treinamento de ator, pode parecer um tanto quanto raso e superficial fora da experiência e contexto de Wilson; o que propomos aqui é pensar o quão importante esse "slowing down" aos dezessete anos foi para Wilson, o quanto, e como, isso alterou a sua forma de ver o mundo e influenciou seus princípios teatrais.

Dilatar o tempo para assim dilatar a percepção de quem faz e de quem vê, essa é a premissa da "câmera lenta" wilsoniana; ampliar as situações, intenções e significados que estão "escondidos" por de trás de determinadas ações, imagens ou cenas. Para Wilson, somente uma dilatação do tempo, e logo, o contato com determinado evento, seria capaz de proporcionar tais descobertas.

Wilson ficou impressionado com uma série de filmes de pesquisas realizadas pelo psiquiatra experimental Dr. Dan Stern, no Instituto Psiquiátrico de Nova Iorque, referentes a mães que cuidavam de seus filhos. Quando exibidos em velocidade normal, os filmes não revelavam muita coisa, a não ser as imagens socialmente aceitas de mães dedicadas, ninando seus filhos com grande paciência. No entanto, quando mostradas em câmera lenta, as fitas transmitiam as mais surpreendentes variações; algumas imagens revelavam nitidamente relances de ódio, pânico, sensualidade, impaciência, repugnância, evasão etc., enfim, reações emocionais que não eram aparentes quando se projetava normalmente o filme [Galizia, 2004, p.108].

A partir desta pequena análise do Dr. Stern a conclusão a que se pode chegar é a de que o ser humano expressa com excessiva rapidez muitas das emoções que ele

\footnotetext{
4 Laboratórios esses realizados em São Paulo durante dezembro de 1973 e abril de 1974, para a preparação de atores brasileiros que comporiam a encenação de A vida e a morte de Joseph Stalin, apresentada no Teatro Municipal da cidade em 1974.

5 Em meados da década de 70, era essa a forma com a qual os primeiros atores da "companhia" de Wilson se auto intitulavam.

6 Dentre as inúmeras entrevistas, analises e reflexões acerca do trabalho de Bob Wilson, principalmente através de nomes como Stefan Brecht (1978), Arthur Holmberg (1996), Luiz Roberto Galizia (2004) e Maria Shevtsova (2007), é possível identificar, mesmo que não explicitamente, que o "estado de relaxamento" proposto por Wilson aproxima-se com diferentes processos de formação do ator, como: os "músculos livres" comentados por Constantin Stankislavski (1989), ou os ideais discutidos dentro do contexto da educação somática, que "quando entramos em um estado de relaxamento da atenção exterior por parte de quem executa o movimento, ou seja, quando penetramos em nosso corpo e agimos de uma forma que não nos permite a reflexão, porém sabemos exatamente o que estamos fazendo. Trata-se de 'libertar o corpo' entregando-o a si próprio" [Coelho, 2010, s/p.].
} 
experimenta, "a ponto de não se poder percebê-las". A comunicação entre os seres humanos em geral é estruturada de modo muito semelhante àquele utilizado pelas mães e seus filhos, nos jogos verbais e visuais [Galizia, 2004. p.108]. Nas palavras de Calvin Tomkins [1975 apud Galizia, 2004, p.45] "É como uma espécie de dança que antecede a palavra, com ações e reações específicas acontecendo o tempo todo".

São as alterações dos processos físicos e imagéticos, ocasionados pela quebra de certos padrões rítmicos convencionais, que surgem através do ralentar das ações e eventos, que nos interessa aqui. Sabe-se que não é apenas Robert Wilson que utiliza esse "procedimento" no teatro, há diversas outras propostas estéticas e linguagens que também o utilizam, como também outras manifestações e campos artísticos que o fazem. Mas, talvez, a diferença entre as encenações wilsonianas e as tantas outras, no contexto teatral, sejam os "porquês": o que se tenta atingir ao ralentar o tempo? Qual a função do ralentar e o que ele ocasiona em quem o faz e em quem o apreende? Quais são essas alterações? Como a circulação sanguínea, por exemplo, é alterada quando o corpo imerge em uma situação ralentada? O que ocorre com a musculatura mais interna do corpo ao movimentar-se? Quais as sensações, imagens e possibilidades dramatúrgicas que este tempo rarefeito sugere? Enfim, quais são as possíveis influências que podem ser auferidas em um corpo-mente inserido em um ambiente ralentado?

Como dito anteriormente, não é apenas no teatro Wilsoniano que vão surgir essas indagações. No cinema, por exemplo, há expoentes que também utilizam do recurso da câmara lenta para tentar alterar a percepção dos agentes que estão incluídos na obra. No entanto, na obra fílmica, o ralentar do tempo agirá principalmente nos espectadores.

Mas... qual espectador?

\section{A "câmera lenta" e a busca por um "novo" espectador. Por quê?}

Foi em dezembro de 1895, em Paris, que os Irmãos Lumière realizaram a primeira apresentação pública de seu invento chamado "cinematógrafo", o filme exibido foi L'Arrivée d'un Train à La Ciotat. A invenção dos irmãos, e o evento que se sucedeu com a sua "exibição", ganharam notoriedade e reconhecimento mundial. Com o passar dos anos esta complexa manifestação estética passou por diversas teorizações, modos de elaboração e reflexões.

Estas reflexões acerca dos processos que envolvem a feitura de uma obra fílmica vão destes as questões que permeiam a composição da obra, como os procedimentos técnicos e estéticos/estilísticos, até as questões que são pertinentes com a recepção da obra por parte dos espectadores.

Como toda manifestação artística, o cinema passou, também, a ser questionado e refletido pelos artistas que o fazem.

No ano de 1926, por exemplo, surgem teóricos, como Semien Timoshenko (1899-1958), que defendiam a ideia do poder absoluto do criador da obra sobre o espectador, cuja atenção seria totalmente manipulada, assegurando-lhe o máximo de passividade e exigindo o mínimo de esforço perceptível por sua parte. Ou seja, o cinema pouparia ao espectador a realização de um trabalho que mobilizasse suas ca- 
pacidades intelectuais. Entretanto, ainda nos anos 1920, e, principalmente no limiar da década de 1930, já começam a surgir discussões contrárias à existência de um espectador meramente passivo. O cineasta e teórico russo Sergei Eisenstein (18981948), começa a pensar e elaborar o cinema como dado novo de percepção, como uma técnica responsável pela construção de um olhar e de uma nova linguagem. Seus escritos apresentam proposições contrárias ao cinema convencional dominante da época, caracterizado, em sua opinião, "como um cinema que utiliza códigos culturais já estabelecidos, limitando ao espectador a possibilidade de uma experiência estética e reflexiva" [Spinelli, 2000. p.22-23].

[...] o filme pode produzir sensações análogas que afetam os órgãos dos sentidos (no caso, os olhos), mas faz isso sem o corretivo dos processos mentais: o cinema tem a ver com o que é materialmente visível e não realmente com a esfera humana do visual. Na percepção do real, o espirito humano não apenas proporciona seu sentido ao real, mas até mesmo suas características físicas: a cor, a forma, o contraste, a luminosidade etc. dos objetos do mundo são produto de operações do espirito, a partir das suas percepções. A visão do espectador é uma atividade criadora do espirito humano [Aumont, 1995 apud Spinelli, 2000, p.23].

É durante os anos 1940 e 1960 que o espectador cinematográfico deixa de ser um simples dado e passa a se tornar um objeto de investigação, como algo ou alguém que precisava estar incluído nos resultados e experiências teóricas. Surgem correntes da psicologia e da teoria do cinema, principalmente com a figura de Rudolf Arnhein (1904-2007) e André Bazin (1918-1958), que passam a insistir no fato de que a visão não é reduzida apenas a uma questão de estímulo da retina, mas sim, como um fenômeno mental que implica todo um campo de percepção, associação e memorização. Ou seja, que se começasse a entender o espectador como alguém que vê além do que o que é mostrado na tela, que realiza, inconscientemente, uma seleção de interesses, e, é justamente no final dos anos 1960, e nas duas décadas seguintes que despontam correntes que se estendem principalmente no debate sobre a "literatura" do cinema: essas correntes pensam o espectador como um interlocutor, alguém a quem uma proposta é dirigida e de quem se espera uma ação-reação; esta corrente tem como base o pensamento alemão da época, bem como as experiências da fenomenologia e da hermenêutica, presentes nos trabalhos de Barthes, Althusser e Derrida [Spinelli, 2000, p. 24-32].

O enfoque dado ao espectador como objeto de investigação, durante o desenvolvimento do cinema enquanto fenômeno artístico, provoca o deslocamento deste como apenas um decodificador da película para um interlocutor. $O$ filme passa a ser comparado a um texto aberto que representa uma construção complexa e dinâmica. Neste sentido, mudando o perfil do espectador, muda-se também a maneira de ver sua presença. Surge um espectador que sofre a influência do ambiente e que interage com o filme para reconstituir o seu sentido. O espectador imagina e cria a partir de imagens.

Ao fazer um levantamento do posicionamento sobre o espectador com relação aos filmes, pretendemos refletir aqui sobre uma visão que englobe o espectador enquanto participante ativo do fazer artístico; quando os múltiplos sentidos e significados de um filme, ou de uma manifestação artística, podem ser atualizados pelo 
espectador em um processo de colaboração.

É através dos filmes, e na figura, do diretor russo Andrei Tarkovsky (1932-1986) que é possível encontrar similaridades ao trabalho de Robert Wilson, principalmente quando se trata da questão de propor ao espectador que ele se torne alguém ativo, alguém que conjuntamente a obra trabalha para criar seus sentidos. Segundo Tarkovsky, "o método pelo qual o artista obriga-o a reconstruir o todo através das suas partes e a refletir, indo além daquilo que foi dito explicitamente, é o único capaz de colocar o público em igualdade de condições com o artista no processo de percepção do filme" [Tarkovsky, 1998, p.20].

Esta condição de igualdade existente entre o público e o artista, proposto por Tarkovsky ao falar de seus filmes, é um dos pontos chave de nossa reflexão: ao não considerar somente o diretor como o único detentor dos processos que permeiam a construção de uma obra artística, torna-se necessário a participação e existência de um espectador ativo. Desta forma, diretor, atores, espectador e todos aqueles que estão inseridos na obra artística são os responsáveis por construir os significados, sentidos, significantes e possibilidades dramatúrgicas da obra.

Tanto Tarkovsky, em seus filmes, quanto Wilson, em seus espetáculos buscam esta espécie de relação com seus espectadores: ambos, ao ralentar o tempo, abrem suas obras para as múltiplas possibilidades interpretativas que estão intrínsecas a individualidade de cada espectador: suas referências externas e internas, sua compreensão de mundo, entre tantas outras coisas.

Tarkovsky trabalha com marcas estilísticas particulares dentro de seu vasto conhecimento sobre a linguagem cinematográfica. Para o cineasta, o fator dominante da imagem cinematográfica é o ritmo, que expressa o fluxo do tempo no interior do fotograma como força organizadora do complexo desenvolvimento dramático e é capaz de alterar a postura perceptiva do espectador.

[...] a imagem cinematográfica nasce durante as filmagens, e existe no interior do quadro. A montagem reúne tomadas que já estão impregnadas de tempo e organiza a estrutura viva e unificada inerente ao filme. A ideia de 'cinema de montagem', onde a montagem combina dois conceitos e gera um terceiro, é incompatível com a natureza do cinema, pois a interação de conceitos jamais poderá ser o objetivo fundamental da arte [Tarkovsky, 1998, p. 135].

É neste aspecto que Tarkovsky acaba indo contra a corrente de pensamento russa dos anos 1920, que tem como principais representantes Eisenstein e Kuleshov. No pensamento de Tarkovsky, "a ideia de montagem como o específico do cinema não possibilita que se estabeleça uma relação entre a experiência pessoal do espectador e o filme projetado diante dele, pois oferece uma interpretação lógica, com um fim em si mesmo, impondo essa atitude ao espectador." Nos seus filmes, o tempo torna-se perceptível quando o espectador sente e percebe algo de significativo e verdadeiro que vai além dos acontecimentos mostrados na tela; quando o que vê no quadro não se esgota em sua configuração meramente visual, ou conceitual, mas é um indício de alguma coisa que se estende para fora do enquadramento. Portanto, sempre há algo a mais por trás do que é mostrado, com isso, permite-se que cada um interprete cada momento a seu próprio modo, através do tempo que flui para além 
dos limites do fotograma [Spinelli, 2000, p.121].

Não é apenas no processo de finalização (edição) dos filmes de Tarkovsky que há esta preocupação com o tempo, os planos sequência7 de seus filmes já são pensados e realizados com esta preocupação espaço-temporal. A montagem de Tarkovsky é poética ao aproveitar todo o fluir da sequência, deixando que o espectador derive neste tempo e espaço.

É em Esculpir o Tempo, que o diretor russo nos relata como, dentro da concepção e elaboração de seu filme intitulado Espelho, é utilizado o recurso da câmera lenta para que possa haver esta participação ativa do espectador, buscando uma alteração no seu sentido e percepções enquanto individuo e, também, no da obra.

[...] alguns fotogramas da cena da tipografia também são filmados em câmera lenta, mas, desta vez, o procedimento é quase imperceptível. Esforçamo-nos para fazer tudo com muito cuidado e sutileza, para que o espectador não se desse conta do ato imediatamente, mas tivesse apenas uma vaga sensação de que algo estranho se passava. Não estávamos tentando enfatizar uma ideia através da câmera lenta; o que pretendíamos era evocar um estado de espírito através de outro meio que não o trabalho do ator [Tarkovsky, 1998, p. 128].

Dilatando o tempo de maneira sutil, Tarkovsky tenta levar o espectador a um outro estado de espirito, apreendendo as imagens de outra forma; em seus filmes isto está ligado à condução e à percepção da dramaturgia, à abordagem das situações e o modo de apreendê-las : estende-se o tempo, para que o espectador possa inserirse na "história", ampliar seu contato com as situações apresentadas, sua apreensão sobre o que está vendo.

Tanto Wilson como Tarkovsky estão interessados em alterações e comunicações sutis da percepção humana. O primeiro utiliza a câmara lenta como meio de evocar intenções e sensações "escondidas" por trás das máscaras presentes no ritmo cotidiano; o segundo, aumentando a quantidade de quadros e películas na filmagem, além do contato com os planos-sequência, sugere uma alteração da atmosfera do filme, que está intrinsicamente ligada com a assimilação do espectador, e diz respeito à condução das situações apresentadas. Ressalta-se, neste momento, que enquanto para Tarkovsky seu enfoque principal se dá para quem acompanha seus filmes, para Wilson esta investigação está presente também, e principalmente, em seus atores.

Estar interessado em outras perspectivas da percepção - as que fogem dos padrões tradicionais - e na busca por transformar o espectador em um ser ativo, acaba por fazer com que Tarkovsky reflita sobre o fato de existir uma parcela do cinema que apresenta uma narrativa linear e uma forma "correta" de ligar os acontecimentos e as imagens, o que, segundo o próprio, acaba por "encarcerar" a mente do espectador: se vê exatamente o que está sendo mostrado, e nada mais. Entretanto, o material cinematográfico

[...] pode ser combinado de outra forma, cuja característica principal é permitir que se exponha a lógica do pensamento de uma pessoa. Este é o fundamento lógico que irá determinar a sequencia dos acontecimentos e a montagem, que os transforma num todo. A origem e o desenvolvimento do pensamento estão

7 Plano que descreve uma ação do começo ao fim sem a utilização de cortes ou decupagem do espaço. 
sujeitos a leis próprias e às vezes exigem formas de expressão muito diferentes dos padrões de especulação lógica. [...] Complexidades do pensamento e visões poéticas do mundo não têm de ser introduzidas à força na estrutura do que é manifestamente óbvio. A lógica comum da sequência linear assemelha-se de modo desconfortável à demonstração de um teorema. Para a arte, trata-se de um método incomparavelmente mais pobre do que as possibilidades oferecidas pela ligação associativa, que possibilitam uma avaliação não só da sensibilidade, como também do intelecto [Tarkovsky, 1998, p.17].

É através das associações poéticas, presente na sensibilidade e no intelecto do espectador, que ele se transforma em um agente ativo no processo artístico; ele (o espectador) passa a participar do processo de descoberta da obra, sem apoiar-se em conclusões já prontas - só tem à sua disposição aquilo que lhe permite penetrar no significado mais profundo dos complexos fenômenos representados diante dele. Afinal, como o próprio Tarkovsky [1998, p.71] diz, as "complexidades do pensamento e visões poéticas do mundo não têm de ser introduzidas à força na estrutura do que é manifestamente óbvio." O cinema, pensado e realizado desta forma, seria, então, capaz de realizar uma manipulação do tempo e, logo, do espaço.

Ao realizar esta manipulação, o diretor cinematográfico torna-se, então, um Escultor do Tempo.

Assim como um escultor toma um bloco de mármore e, guiado pela visão interior de sua futura obra, elimina tudo que não faz parte dela - do mesmo modo o cineasta, a partir de um "bloco de tempo" constituído por uma enorme e sólida quantidade de fatos vivos, corta e rejeita tudo aquilo de que não necessita, deixando apenas o que deverá ser um elemento do futuro filme... [Tarkovsky, 2002, p.76].

É uma visão do mundo subjetiva, e ímpar, que faz com que tanto Tarkovsky quanto Wilson insistam na quebra dos padrões lógicos do pensamento. A partir da análise de suas reflexões é possível concluir que ambos, cada qual em sua área, acreditam que ao se quebrar a referência rítmica que se espera, inconscientemente, que ocorra em determinas ações e/ou situações, altere-se, também, a lógica do pensamento e de assimilação de mundo das pessoas que apreendem tais ações e/ou situações - os atores e os espectadores.

Ainda neste contexto, sobre o quão uma alteração espaço-temporal é propulsora de manifestações outras no corpo-mente, trinta anos mais tarde, analisando neurologicamente pacientes que sofriam de fortes enxaquecas, o neurologista e escritor Oliver Sacks (1933 - 2015) acaba encontrando semelhanças no relato de alguns pacientes com algumas características oriundas do cinema. De certa forma, Sacks acaba por enfatizar as ideias que Tarkovsky tivera ao afirmar que "os recursos técnicos e conceituais do cinema - zoom - 'fade out', dissolução, omissão, alusão, associação e justaposição de todos os tipos - imitam de perto o fluxo e desvios da consciência" [Sacks, 2004, p.5].

Não há linearidade na forma com a qual nossos pensamentos fluem, cada pessoa cria suas associações imagéticas, referenciais e de sentido/significado com base em suas experiências e bagagens individuais. A forma com a qual cada sujeito assimilará o contato com uma dilatação espaço-temporal, ou suas vertentes, dificilmente pode ser especificada, uma vez que ela será única e particular a cada indivíduo. Contudo, é 
desta forma que Wilson e Tarkovsky nos propõem essa experiência rítmica-temporal em suas obras: eles não sabem de qual forma isto afetará as pessoas, mas sabem que de alguma forma, ela os afetará.

\title{
O Ato de Fotografia
}

Quando Wilson solicita que seus atores estejam relaxados - permitindo que a energia de seus corpos possa fluir - soma a isso o ritmo ralentado de suas encenações. Desta forma, espera que os espectadores apreendam a obra de forma tão relaxada a ponto de deixarem a energia e a percepção fluírem e "se o sono se aproximar, as piscadas naturais de seus olhos terminarão por levar ao cérebro uma coleção de imagens que se gravarão com muito mais vigor do que o fluxo regular daquelas imagens que eles absorvem sem perceber" [Galizia, 2004. p. 117], esta experiência é conhecida como "Ato de Fotografia".

\begin{abstract}
Além de cochilar, as pessoas piscam mais, quando assistem a uma peça de Wilson. Ele afirma que isso se deve ao fato de tudo ser ralentado. É uma espécie de ajustamento. 'Nessas peças, os espectadores evidentemente piscam mais. $\mathrm{O}$ ato de piscar, porém, modifica nossas percepções e é o que eu quero. As imagens interiores tornam-se mais misturadas com as imagens exteriores'. O que acontece na realidade é um equilíbrio de ritmos. Sendo a imagem exterior lenta, o olho apreende com maior rapidez o que é visto. As imagens exteriores e interiores começam a ajustar-se umas às outras e a imaginação de quem vê caminha com velocidade cada vez maior. [...] No teatro de Wilson, a plateia goza de um tempo a mais. Essa combinação de piscar e dormir é fundamental para a experiência do espectador [Galizia, 2004. p.154].
\end{abstract}

Embora nem todas as obras de Wilson sejam tão grandes quanto $A$ vida e a morte de Joseph Stalin, de doze horas de duração, ou KAMOUNTain and GUARDenia Terrace, sete dias e sete noites, elas são suficientemente longas para provocar reações diversas nos indivíduos envolvidos, tanto dentro como fora de cena. As encenações têm mais a ver com a sua duração, as repetições constantes, as músicas, os momentos silenciosos e outros acontecimentos semelhantes que acabam por contribuir para provocar um estado de "semi-adormecimento, que excita a imaginação da plateia. Wilson não se preocupa com o fato de que muitos espectadores chegam a dormir durante a peça. Quer que eles tenham tempo de pensar" [Galizia, 2004. p.152].

Por volta da década de 1960, juntamente com o desenvolvimento das encenações de Wilson, e o surgimento de outras formas de se "olhar" para o espectador, o neurologista Oliver Sacks cria, e passa a analisar, o termo/condição chamado de "visão cinematográfica". Este distúrbio neurológico, raro, ocorre nos indivíduos durante ataques de enxaqueca, quando as vezes acabam por perder o senso de continuidade e movimento visual, e, em lugar disso, enxergam uma séria sincopada de imagens paradas. $O$ efeito, descrito pelos próprios pacientes, é comparável a um filme projetado lentamente demais. O ritmo das oscilações nesses episódios parece ser de 6 a 12 por segundo - levando em conta que nos cinemas convencionais são transmitidos 24 quadros por segundo, ao ocorrer essas crises, as pessoas chegam a ver e apreender o mundo cerca de 2 a 3 vezes mais lento do que o convencional. [Sacks, 2005. p.6] 
Enxergar e existir em um "mundo lento", mesmo que seja por poucos minutos, cria certos fluxos de pensamento e percepção psicofísicas únicos nesses indivíduos. Todas as imagens visuais ao redor se desaceleram, se, por exemplo, a pessoa estiver conversando com outra, os lábios começarão a se mexer de forma lenta, mas o som será ouvido no ritmo convencional.

Os fluxos e alterações de pensamento são diretamente proporcionais à dilatação ou aceleração do tempo. O próprio Tarkovsky diz que "a consciência humana depende do tempo para existir" [1998, p.65]. Logo, não há como estudar as diversas implicações e qualidades artísticas e sensitivas ligadas à dilatação do tempo sem dar a devida atenção à consciência e a mente humana.

Embora o "ato de fotografia" de Wilson e a "visão cinematográfica"8 de Sacks, tenham em suas denominações um termo que faz menção à captação de imagens congeladas, abrangem, também, questões intrinsicamente ligadas ao ver, existir e perceber o mundo. Na fotografia o que temos é uma única imagem, um quadro, já no cinema uma sucessão continua e rápida de imagens que dão a sensação de movimento justamente pela velocidade com a qual esses quadros passam por nossos olhos. É neste quesito que as duas nomenclaturas dialogam: ambas tratam da imagem e de como o jeito com que ela é apreendida seja capaz de influenciar as torrentes de pensamento e sensações.

Enquanto no teatro de Robert Wilson o que ocorre é essa apreensão mais lenta do mundo, ocasionada pelo ato de fotografia, os pacientes de Oliver Sacks sofrem de uma condição neural que independe de suas vontades ou da influência de algum estímulo externo. Nos dois casos o mundo passa a ser percebido e apreendido de outra forma, em uma, num ambiente fictício, "seguro", noutra, a qualquer instante; as duas são causadas por um ralentar do tempo que influencia e abrange o sistema neural, mas, enquanto uma é uma doença, a outra é provocada.

Outro paciente de Sacks acaba por apresentar um outro distúrbio neurológico capaz de dialogar com o teatro "estático" de Wilson: neste distúrbio, a apreensão das imagens exteriores não apenas desacelera, como também, pode chegar a um congelamento total, de segundos ou minutos. "Congelamentos de imagem como esses mostram que a consciência pode ser parada, interrompida, por períodos substanciais, enquanto as funções automáticas, não conscientes, como a respiração e a manutenção da postura, continuavam como antes." Sacks chegou à conclusão de que o "fluxo normal da consciência não apenas podia ser fragmentado, quebrado em pedaços pequenos, como instantes, como também podia ser suspenso de maneira intermitente, por horas a fio" [2005. p.6]. Quando Wilson propõe uma dilatação do tempo, esta acaba por levar automaticamente a uma dilatação do espaço, cria-se uma atmosfera suspensa, uma espécie de inação; por alguns instantes supõe-se que nada está acontecendo, contudo, enquanto parece que nada ocorre no palco, internamente o corpo continua a pulsar, continua a ser e a (co)existir no mundo.

8 A principal diferente entre a fotografia e o cinema é de que a primeira é capaz apenas de registrar o espaço, e, a segunda, além do espaço, capta, também, o tempo. 
no tempo, organizamos o tempo, somos criaturas totalmente temporais [Sacks, 2004. p.5]

A sensação de vazio, de algo que permanece incompleto nas encenações de Wilson é algo convencional. Prolongando a noção do tempo, acaba-se por estender as ações e elas podem parecer incompletas, busca-se, de certa forma, criar uma sensação de suspense, onde, o "clímax dramático pode não ser importante ou excitante (brigas, tiros), mas suas preliminares, aparentemente não dramáticas, são excitantes e importantes. As catástrofes não são dramáticas, só a expectativa da catástrofe" [Galizia, 2004. p.22].

Chega a ser um tanto quanto irônico insistir que Bob Wilson trabalha com a câmara lenta em prol de uma possível alteração de assimilações físicas quando o mesmo considera que em seu modo de fazer teatral não exista esta dilatação do tempo, ele afirma que apenas dá o tempo "certo" para que as coisas ocorram. Em uma entrevista para o jornal americano The New York Times, o encenador é categórico a afirmar que

Isso esta errado. Não é em câmera lenta, é no tempo natural. A maioria dos espetáculos lida com um tempo acelerado das coisas, mas eu uso uma espécie de tempo natural no qual as coisas demoram para acontecer, como o sol para se por, uma nuvem para mudar, um dia para terminar. Eu dou tempo para refletir, para meditar sobre outras coisas além daquelas que acontecem no palco. Eu dou tempo e espaço para se pensar ${ }^{9}$ [Wilson, 02 dez 1984].

O ato de provocar uma apreensão mais lenta do mundo, ralentando as ações e as situações, abrange não apenas o público, mas é algo que influi, também, como já salientamos, nos agentes que compõem a obra. Não é simplesmente desacelerar as ações, realizá-las de forma lenta e precisa, é, antes de tudo, compreender este ralentar da forma mais orgânica possível, nas camadas mais profundas do corpo, e, logo, da consciência.

Os indivíduos-pacientes de Sacks e os filmes de Tarkovsky são apenas dois exemplos de como a dilatação do tempo é propulsora e modificadora de sentidos e apreensões. Em Sacks temos esta dilatação em caráter puramente interno, em Tarkovsky, de forma intrinsicamente externa a nós. Em Wilson, o processo principia dos atores e da encenação para, então, chegar ao público.

São três áreas do conhecimento distintas e interconectadas. São três pesquisadores, em momentos e realidades diferentes, porém, os três partem do princípio de que uma imersão em um espaço-temporal expandido seja capaz de alterar os processos de compreensão, apreensão e significação, assim como os processos sensitivos, cognitivos e imagéticos das pessoas.

A alteração espaço-temporal que Wilson propõem em seus espetáculos se dá, principalmente, por meio de dois processos: a "câmara lenta" e o "ato de fotografia"; é através destas duas ferramentas que o encenador lança mão em prol de que o ralentar rítmico possa agir sobre os estados psicofísico dos atores e dos espectadores.

9 That's wrong. It's not in slow motion; it's in natural time. Most theatre deals with speeded-up time, but I use the kind of natural time in which its takes the sun to set, a cloud to change, a day to dawn. I give you time to reflect, to meditate about other things that those happening on the stage. I give you time and space in which to think [Robert Wilson]. 
A partir dessa breve reflexão entre as experiências de Wilson, Tarkovsky e Sacks, é possível verificar que uma imersão em um espaço-temporal dilatado é capaz de alterar a percepção - e apreensão - de um sujeito, com uma ressalva: ela ocorre de forma particular a cada indivíduo, como consequência de suas experiências, expectativas e associações construídas ao longo de sua vida.

\section{Referências}

ABSOLUTE Wilson. Direção Katharina Otto-Bernstein. Estados Unidos. Film Manufactures, 2006. DVD (105min)

BRECHT, Stefan. The Theatre of Visions - Robert Wilson. Frankfurt: Suhrkamp Verlag Franfurt, 1978.

COELHO, Marcelle Teixera. Sujeito objeto: o corpo no teatro de formas animadas na perspectiva da educação somática. In: VI CONGRESSO ABRACE, 2010, Belo Horizonte. Anais Do Congresso De Pesquisa E Pós-Graduação Em Artes Cênicas. Belo Horizonte.

GALIZIA, Luiz Roberto Brant de Carvalho. Os Processos criativos de Robert Wilson: trabalhos de arte total para o teatro americano contemporâneo. Tradução do autor e Carlos Eugenio Marcondes de Moura. São Paulo: Perspectiva,2004.

HOLMBERG, Arthur. Directors in Perspective: The Theatre of ROBERT WILSON. Massachusetts: Cambridge University Press, 1996.

SACKS, Oliver. A Torrente da Consciência. Folha de São Paulo. São Paulo, 15 de fev., 2004. Caderno Mais+!, p.5

Vendo Vozes - Uma viagem ao mundo dos Surdos. Tradução de Laura Teixeira Morta. São Paulo: Companhia das Letras, 2010.

O homem que confundiu sua mulher com um chapéu. Tradução de Laura Teixeira Morta. São Paulo: Companhia das Letras, 1997.

SHEVTSOVA, Maria. Robert Wilson. New York: Taylor \& Francis Group, 2007.

SPINELLI, Egle Muller. Solaris E Stalker: Aplicação De Uma Poética Na Área Transicional De Jogo Entre Filme-Espectador. 2000. Dissertação (Mestrado em Multimeios) Instituto de Artes, Universidade Estadual de Campinas, Campinas.

STANISLAVSKI, Constantin. Manual do ator. São Paulo: Martins Fontes, 1989.

TARKOVSKY, Andrei. Esculpir o Tempo. Tradução de Jefferson Luiz Camargo. - 2ª 
ed. - São Paulo: Martins Fontes, 1998.

Recebido em: 16/01/2016

Aprovado em: 11/07/2016 